\title{
Apuntes para una genealogía del poder en la era digital
}

Notes for a Genealogy of Power in the Digital Age

Anotacions per a una genealogía del poder a l'era digital

Joel Jair Contreras García

UAM-I, México

erostrato999@yahoo.com.mx

Recibido: $30 / 10 / 2021$

Aceptado: 24/12/2021 
Resumen En el artículo se propone un estudio del poder en la época digital a partir de las propuestas teóricas de Michel Foucault y Gilles Deleuze que parten de la metodología genealógica, planteando que un desarrollo de sus teorías permitiría comprender la problemática de la sociedad capitalista actual como la instauración de un apartheid online y las alternativas de una filosofía intempestiva, que criticaría las dinámicas de las nuevas formas de la sociedad capitalista conceptualizada como una sociedad del control.

Palabras Capitalismo, control, poder, genealogía.

clave

Abstract The article proposes a study of power in the digital age from the theoretical proposals of Michel Foucault and Gilles Deleuze that star form the genealogical methodology, proposing that a development of their theories would allow us to understand the problems of current capitalist society such as the establishment of an online apartheid and the alternatives of an untimely philosophy, which would criticize the dynamics of the new forms of capitalist society conceptualized as a society of control.

Keywords Capitalism, Control, Power, Genealogy.

Resum En l'article es proposa un estudi del poder en l'època digital a partir de les propostes teòriques de Michel Foucault i Gilles Deleuze que parteixen de la metodología genealógica, plantejant que un desenvolupament de les seves teories permetria comprendre la problemática de la societat capitalista actual com la instauració d'un apartheid en línea i les alternatives d'una filosofia intempestiva, que criticaría les dinàmiques de les noves formes de la societat capitalista conceptualitzada con una societat del control.

Paraules Capitalisme, control, poder, genealogía.

\section{clau}




\section{Introducción}

La actualidad puede ser calificada como una época de la novedad, por la innovación tecnológica predominante en todos los dominios de la vida cotidiana, pero también, como una época de incertidumbres no solamente por la originalidad sin precedentes de las tecnologías de la informática y las telecomunicación, así como, por sus aplicaciones y sus usos; sino, sobre todo, por sus consecuencias, que aún están por verse de manera definitiva, en el mundo del ser humano -cultura, sociedad y medio ambiente-, tan graves o quizá más que los efectos actuales, y los proyectados por la ciencia, en la naturaleza amenazada por una crisis climática y ecológica, también sin precedentes, que en su informe Making Pace With Nature de 2021 la ONU califica como un emergencia medioambiental:

El planeta se enfrenta a una triple emergencia medioambiental ligada al cambio climático, la contaminación y la pérdida de biodiversidad. Y, según advierte Naciones Unidas, estas tres crisis suponen una seria amenaza para la humanidad. «El mundo está incumpliendo sus compromisos de limitar los daños ambientales» (...) Y las conclusiones son muy negativas: la Tierra se encamina hacia un incremento de temperatura de al menos tres grados respecto a los niveles preindustriales; más de un millón de especies de animales y vegetales del mundo están en peligro de extinción; y las enfermedades vinculadas a la contaminación acusan cada año unas nueve millones de muertes prematuras... ${ }^{1}$

En este sentido, es necesario situarse más allá del optimismo ingenuo con el que los empresarios y trabajadores de corporativos nos tratan de presentar las bondades y cualidades de tales transformaciones, en los términos de la igualdad y la comunicación de una aldea global que en los hechos se caracteriza por enfatizar el egoísmo, el aislamiento, la competitividad y el cálculo en provecho de las proyecciones económicas de sus negocios cuya prosperidad depende de la pobreza de la mayor parte de la humanidad, la devastación de los recursos naturales y la destrucción de las relaciones sociales. Por ello, es preciso entender tales transformaciones como el surgimiento de un nuevo tipo de sociedad capitalista, una modificación radical de la sociedad capitalista basada, organizada e impuesta a partir de nuevos principios y dinámicas que es posible conceptualizar como un nuevo tipo de poder basado en la tecnología informática. Nueva sociedad capitalista que el pensamiento crítico ha tratado de teorizar de manera visionaria desde la década de los setenta del siglo pasado cuando aparecían sus primeras manifestaciones en los desarrollos tecnológicos, las transformaciones sociales y los procesos económicos.

En este texto expondremos de manera básica los planteamientos propuestos por Michel Foucault y Gilles Deleuze para conceptualizar este nuevo tipo de

${ }^{1}$ Planelles M. (18/02/21). La ONU alerta de una triple crisis: calentamiento, pérdida de biodiversidad y contaminación. El País. 
sociedad, y sobre todo, su nuevo tipo de poder basado en las tecnologías informáticas, que producirán nuevas relaciones, instituciones y subjetividades en torno al poder de la vigilancia permanente, a distancia y omnipresente en espacios abiertos, es decir, el control. Sin dejar de considerar, e incluso, recuperando algunas de las importantes aportaciones en el tema de la transformación de la sociedad capitalista en relación a las tecnologías de la informática y las telecomunicaciones de Buyng Chul Han (la sociedad de la transparencia, la psicopolítica), Zuboff (capitalismo de vigilancia) y Lazzarato (máquinas semióticas), en este trabajo optamos por plantear la posibilidad de una propuesta teoríca más próxima a la genealogía nietzscheana.

\section{El apartheid mundial online}

Las innovaciones en las formas del trabajo, el consumo, el entretenimiento y la comunicación posibilitadas por las tecnologías de la informática y las telecomunicaciones no implican sólo una modificación o un perfeccionamiento de las formas previas, sino, en muchos casos el surgimiento de nuevas formas que dando continuidad a las funciones anteriores las intensifican como sucede con las dinámicas de explotación y acumulación de riqueza capitalistas que utilizan las tecnologías de la informática y las telecomunicaciones para potencializar sus procesos de maneras inimaginables hasta entonces, concentrando de manera planetaria los mercados en monopolios mundiales que permiten la circulación omnipresente e instantánea del capital, y lo que es más importante, la concentración radical de la riqueza planetaria en las manos de los dueños de unas cuantas empresas. La concentración radical de la riqueza consiste no solamente en la apropiación del trabajo de la mayor parte de la humanidad, sino también, de los recursos naturales y de la cultura convertidos en mercancías, pues si alguna continuidad existe entre las formas sociales previas y las actuales es la planetarización de los mercados y la mercantilización de todo aquello que pueda ser apropiado aunque se trate de lo más propio de las comunidades, como su cultura, o necesario para su sobrevivencia como los recursos naturales. ${ }^{2}$

Es decir, que se trata del perfeccionamiento e intensificación de las dinámicas de la sociedad capitalista que a través de nuevos medios se quita máscaras y supera límites que en su origen le fueron necesarios para imponerse a la sociedad anterior y enfrentarse a sus rivales políticos -el discurso político estatal y sus garantías políticas liberales, que permitieron la conformación de los mercados nacionales

\footnotetext{
${ }^{2}$ Como lo plantearon Deleuze y Guattari, en sus dos tratados sobre capitalismo y esquizofrenia, el capitalismo financiero establece una dinámica semiótica de descodificación de la riqueza convertida en información, lo que permite la apropiación de todo tipo de recursos y su circulación instantánea en la forma de la telecomunicación informática; es decir, que la tecnología informática y el uso de las telecomunicaciones tienen como principal propósito convertirlo todo en mercancías y su intercambio comercial en procesos planetarios de acumulación de riqueza.
} 
necesarios para la producción industrial y el poder político que garantizaba el derecho de propiedad-, sustituidos por la legitimidad de una ideología del librecambismo radial cuya política es la macroeconomía y su justificación una idolatría del progreso tecnológico que de manera fanática cree en las necesarias bondades del desarrollo tecnológico, como si la tecnología y sus innovaciones lo mejorarán todo necesariamente con su sola participación o uso; cuando lo que sucede es lo contrario, pues las tecnologías se están utilizando para intensificar los procesos de devastación de la naturaleza y destrucción de las relaciones sociales con las formas irracionales de producción y consumo capitalistas. Puesto que, como señala Deleuze en el Postescriptum: sobre las sociedades de control, la tecnología y sus usos forman parte y son expresión de la sociedad en que ha sido producida:

Es sencillo buscar correspondencias entre tipos de sociedad y tipos de máquinas, no porque las máquinas sean determinantes, sino porque expresan las formaciones sociales que las han originado y que las utilizan. Las antiguas sociedades de soberanía operaban con máquinas simples, palancas, poleas, relojes; las sociedades disciplinarias posteriores se equiparon con máquinas energéticas, con el riesgo pasivo de la entropía y el riesgo activo del sabotaje; las sociedades de control actúan mediante máquinas de un tercer tipo, máquinas informáticas y ordenadores cuyo riesgo pasivo son las interferencias y cuyo riesgo activo son la piratería y la inoculación de virus. No es solamente una evolución tecnológica, es una profunda mutación del capitalismo (Deleuze, 1996: 252).

De tal manera, el mito o la fantasía de una aldea global sede el paso a la realidad de un nuevo tipo de sociedad que es preciso comprender en sus mecanismos y relaciones concretas para de alguna manera empezar a responder a las incertidumbres que plantea la falsa imagen de una aldea que se convierte en su opuesto, una isla conectada por internet, un apartheid mundial online de un puñado de privilegiados que una vez acaparada la riqueza planetaria a grados tan grandes como absurdos, se protege de masas de miserables que carecen de todo, que son inútiles para el trabajo automatizado y demasiados para ser encerrados, por lo que se utiliza la misma tecnología que se usó para privatizar y despojarlos de sus recursos naturales y condiciones sociales de vida para vigilarlos, predecir e inducir su comportamiento; es decir, para controlarlos se les confina en guetos cuyas muros están constituidos por datos y claves de acceso a los servicios de los monopolio mundiales, por lo que el apartheid online funciona concentrando de manera radical cada vez más riqueza y despojando de ella a poblaciones enteras, por lo que en la medida en que concentra más riqueza los guetos de pobreza aumentan convirtiéndose en archipiélagos de 
guetos $^{3}$ que en su búsqueda por acceder a ella orbitan en torno a una isla cada vez más pequeña que los rechaza, y que en su dinámica va expulsando a cada vez más individuos destruyendo sus comunidades como lo testimonia el aumento de la pobreza en los denominados países del primer mundo y los procesos migratorios de los denominados países subdesarrollados. ${ }^{4}$ En ese sentido, Deleuze afirma: «Sin duda, una constante del capitalismo sigue siendo la extrema miseria de las tres cuartas partes de la humanidad, demasiado pobres para endeudarlas, demasiado numerosas para encerrarlas: el control no tendrá que afrontar únicamente la cuestión de la difuminación de las fronteras, sino también la de los disturbios en los suburbios y guetos (Deleuze, 1996: 253)».

En estos términos, la inclusión y la exclusión en la nueva sociedad capitalista se da en la dimensión de la virtualidad de los datos y las claves que posibilitan o niegan el acceso a los satisfactores, bienes y servicios, ${ }^{5}$ puesto que el apartheid mundial y los archipiélagos de guetos aunque se localicen en cierto modo aún en la geografía económica y política estatal su territorialidad está conformada por la participación intensiva en los intercambios comerciales online, es decir, por formar de parte o no de la pequeña isla que concentra la riqueza social y natural, ${ }^{6}$ por lo que, tanto la isla

${ }^{3}$ «Si observan un mapamundi en este periodo -el final de la Tercera Guerra Mundial-y analizan los últimos ocho años, ha habido una recomposición sobre todo en Europa, pero no sólo. Donde antes había una nación ahora hay muchas naciones, el mapamundi se ha fragmentado. Este es el efecto paradójico que está ocurriendo a causa de esta Cuarta Guerra Mundial. En lugar de que se globalice, el mundo se fragmenta y en lugar de que este mecanismo hegemonice y homogenice, van apareciendo cada vez más los diferentes. La globalización y el neoliberalismo están haciendo del mundo un archipielago. Y hay que darle una lógica de mercado, organizar estos fragmentos en un común denominador (...) En suma, lo que quiere hacer este gran mercado es convertir todas estas islas no en naciones, sino en centros comerciales... (Subcomandante Insurgente Marcos, 2017; 160).»

${ }^{4}$ Es importante señalar que la dinámica radicalizada de acumulación y concetración de riqueza funciona con la misma intensidad al interior del apartheid, produciendo una desigualdad cada vez mayor entre los miembros de los centros de acumulación de riqueza y la expulsión de los más pauperizados, pues las dinámicas de concentración de riqueza que hasta mediados del siglo XX permitían un bienestar social y una distribución de la riqueza en los países desarrollados, como una medida para contar con una población mínima de consumidores que permitiera la circulación del capital, son sustituidas por las nuevas dinámicas económicas que prescinden de esas poblaciones convirtiéndolas también en prescindibles, como se puede observar en el aumento de la pobreza e incluso indigencia en los países desarrollados.

${ }^{5}$ «En cambio, en las sociedades de control, lo esencial ya no es una marca ni un número, sino una cifra: la cifra es una contraseña [mot de passe], en tanto que las sociedades disciplinarias están reguladas mediante consignas [mots d'ordre] (tanto desde el punto de vista de la integración como desde el punto de vista de la resistencia a la integración). El lenguaje numérico de control se compone de cifras que marcan o prohíben el acceso a la información... (Deleuze, 1996: 251).»

${ }^{6}$ Es un error plantear que el sólo uso de las tecnologías de la informática implica la participación plena en las nuevas formas de socialización basadas fundamentalmente en el inetercambio comercial, pues a diferencia de los aplogístas ingenuos de la tecnología de la informática y las telecomunicaciones un estudio crítico debe plantear que la forma de participación efectiva y real en la socialidad de las nuevas tecnologías es comercial, pues la lógica de la ganancia es lo que establece las dinámicas, principios y prácticas de los servicios e interacción en internet, por ello, la participación en el apartheid no es para todos los usuarios de internet sino sólo para aquellos con el poder adquisitivo para participar en el intercambio comercial que pemite el acceso a los recursos y bienes sociales, naturales y culturales. 
como los guetos son y pueden ser móviles a diferencia de la localización fija de las relaciones institucionales de las formas sociales anteriores, posibilitando y replicando el movimiento del capital. En este sentido, es que Deleuze habla de nuevos espacios abiertos propios del control que secundando las posibilidades de movimiento del capital financiero, hecho posible por las tecnologías de la información, participan de nuevas formas de circulación del capital, en proceso productivos y consuntivos móviles en el espacio planetario, con empresas capaces de realizar actividades comerciales y transacciones financieras de manera instantánea en cualquier y desde cualquier parte del planeta; por lo que el carácter abierto de las nuevas instituciones sociales y de los procesos económicos implica las condiciones materiales para una nueva circulación del capital que lo convierten en omnipresente para subsumir la riqueza de todos los territorios y comunidades.

No es un capitalismo de producción sino de productos, es decir, de ventas o de mercados. Por eso es especialmente disperso, por eso la empresa ha ocupado el lugar de la fábrica (...) Un mercado se conquista cuando se adquiere su control, no mediante la formación de una disciplina; se conquista cuando se pueden fijar los precios, no cuando se abaratan los costes de producción; se conquista mediante la transformación de los productos, no mediante la especialización de la producción (Deleuze, 1996: 252).

A pesar de la radicalidad de los cambios experimentados el nuevo tipo de sociedad no termina aún de definirse, por lo que se continúa caracterizando por la incertidumbre, ya que por una parte las instituciones, estructuras y relaciones sociales, es decir, los poderes de la forma social anterior aún no logran encontrar su lugar en el nuevo tipo de sociedad o terminan por ser excluidos de ella, como sucede con las instituciones del Estado nación, y por otra, los agentes y las nuevas instituciones no terminan por definir de una manera clara no solamente las relaciones con los agentes e instituciones anteriores, sino, la especificidad, y sobre todo, el alcance de su poder, pues aún están conformando las estructuras y dinámicas de nuevas formas de relaciones sociales en el establecimiento e imposición del apartheid social,7 que dependerá de la capacidad de resistencia, rechazo y organización por parte de los gobiernos estatales, pero sobre todo, de la capacidad de organización y respuesta de poblaciones y comunidades locales en la defensa de sus territorios, recursos naturales y patrimonio cultural.

\footnotetext{
${ }^{7}$ Un ejemplo paradigmático de esto es la regulación de los denominados gigantes de internet (Facebook, Google, Appel y Amazon) en relación a la privacidad, al uso comercial y político de los datos de los usuarios, así como, a la reglamentación de sus actividades comerciales, cada vez más monopólicas y diversificadas, o sus responsabilidades civiles y políticas; cuestiones que plantean tanto la hegemonía de los mercados internacionales como las formas de las nuevas democracias que determinarán el alcance del poder de tales empresas y el lugar de las instituciones políticas estatales.
} 


\section{La genealogía del poder}

Los esfuerzos de una parte importante de la filosofía contemporánea consisten en elaborar una nueva crítica capaz no solamente de identificar las manifestaciones de esta nueva forma de sociedad, sino en la medida de las posibilidades, realizar un diagnóstico que permita prever las dinámicas, principios y relaciones que establecerá para permitir encontrar formas de lucha y resistencia. Estos esfuerzos tienen en la filosofía de Michel Foucault y Gilles Deleuze, unos de los pioneros más importantes que asumiendo una analítica materialista tratan de identificar y diagnosticar las nuevas modalidades del poder que producirá una nueva época que en sus términos aún está por definirse y que se caracteriza por la amenaza de una incertidumbre calculada por la dinámica capitalista, es decir, que lo incierto de tales transformaciones se ubica en los límites del cálculo instrumental que busca reducirlo todo a una mercancía que concentre la riqueza en cada vez menos personas, por lo que la incertidumbre sólo se referiría a la velocidad y las personas o empresas que llevarían a cabo tales procesos sin dejar posibilidad ni alternativa a otras dinámicas o posibilidades sociales. Por ello, es que su analítica materialista del poder se presenta como una filosofía intempestiva, un pensamiento de lo intempestivo que busca ser inactual o lo inesperado que irrumpe contra y más allá de las dinámicas establecidas o que se propone imponer, es decir, una filosofía que piensa y propicia lo inesperado por los cálculos de los poderes vigentes, un pensamiento que busque irrumpir e interrumpir el tiempo de la incertidumbre cuya únicas variables son la velocidad y los actores de una crisis inevitable.

La analítica del poder con la que Foucault y Deleuze tratan de teorizar las nuevas formas de la sociedad capitalista se basa y busca desarrollar el método genealógico de Nietzsche, según el cual, todo fenómeno es la manifestación y concreción de las luchas de fuerzas que se han desarrollado a lo largo de un proceso que les da forma, por lo que, el estudio y la comprensión de cualquier fenómeno consiste en el estudio de su origen, no como el despliegue de una esencia sino como el estudio de los detalles y accidentes que han conformado su proceso constructivo; la historia se convierte entonces en la historia de los orígenes pero no de un origen trascedente que forma parte de un metarrelato, sino en la historia de los específico y el detalle que busca conocer la conformación y constitución de los fenómenos, y con ello, del valor y del poder, ${ }^{8}$ pues todos los fenómenos tienen un origen inmanente que es

\footnotetext{
${ }^{8}$ «... necesitamos una crítica de los valores morales, hay que poner alguna vez en entredicho el valor mismo de los valores - y para esto se necesita tener conocimiento de las condiciones y circunstancias de que aquellos surgieron, en las cuales se desarrollaron y modificaron (la moral como consecuencia, como síntoma, como máscara, como tartufería, como enfermedad, como malentendido pero también la moral como causa, como medicina, como freno, como veneno), un acontecimiento que hasta ahora ni ha existido ni tampoco se lo ha siquiera deseado (Nietzsche, 2000: 28).»
} 
posible y necesario conocer. ${ }^{9}$ En estos términos, el poder es conceptualizado como una instancia productiva, una relación de fuerzas que produce de acuerdo a sus características y especificidades un tipo de valores, relaciones y instituciones sociales, es decir, un tipo de sociedad.

Nunca encontramos el sentido de algo (fenómeno humano, biológico o incluso físico), si no sabemos cuál es la fuerza que se apropia de la cosa, que la explota, que se apodera de ella o se expresa en ella. Un fenómeno no es una apariencia ni tampoco una aparición, sino un signo, un síntoma que encuentra su sentido en una fuerza actual (...) En general, la historia de una cosa es la sucesión de las fuerzas que se apoderan de ella, y la coexistencia de las fuerzas que luchan por conseguirlo. Un mismo objeto, un mismo fenómeno cambia de sentido de acuerdo con la fuerza que se apropia de él (Deleuze, 2008: 10).

En este sentido, Foucault parte de la tesis básica de que el poder es productivo, es decir, entiende el poder no como un atributo, una característica o una propiedad, sino, como una relación entre fuerzas. El poder entendido como una relación de fuerzas, Foucault lo recupera elementalmente de la metodología genealógica de Nietzsche, según la cual, cualquier cosa y particularmente las relaciones políticas y morales, se explican históricamente al estudiar sus orígenes, es decir las prácticas, acciones e ideas que conformaron los procesos en los que un valor, institución o poder fue constituido.

Ahora bien, el estudio de esta microfísica supone que el poder que en ella se ejerce no se conciba como una propiedad, sino como una estrategia, que sus efectos de dominación no sean atribuidos a una «apropiación», sino a unas disposiciones, a unas maniobras, a unas tácticas, a unas técnicas, a unos funcionamientos; que se descifre en él una red de relaciones siempre tensas, siempre en actividad más que un privilegio que se pueda detentar; que se le dé como modelo la batalla perpetua más que el contrato que opera una cesión o la conquista que se apodera de un territorio (Foucault, 2001: 34).

La genealogía consiste en estudiar la historia no como el desarrollo teleológico de un gran relato, sino, como el conjunto de las acciones y accidentes específicos que en la historia han conformado el estado particular o la situación de un fenómeno. En este sentido, el estudio del poder consiste en estudiar las acciones, prácticas e

${ }^{9}$ «Genealogía quiere decir a la vez del origen y origen de los valores. Genealogía se opone a la vez al carácter absoluto de los valores como a su carácter relativo o utilitario. Genealogía significa el elemento diferencial de los valores de los que se desprende su propio valor. Genealogía quiere decir pues origen o nacimiento, pero también diferencia o distancia en el origen. Genealogía quiere decir nobleza y bajeza, nobleza y vileza, nobleza y decadencia en el origen. Lo noble y lo vil, lo alto y lo bajo, tal es el elemento propiamente genealógico o crítico... (Deleuze, 2008: 9).» 
ideas que históricamente han determinado o producido las relaciones de fuerza entre los individuos y grupos de una sociedad; por ello, la concepción del poder y su determinación, dependen de las prácticas, acciones y accidentes que en específico han sucedido en relación a los fenómenos sociales como relaciones entre individuos y grupos sociales.

En tal estudio de las determinaciones específicas de lo político Foucault propone atender, explicar e interpretar los procesos históricos que han caracterizado al poder, entendiendo que tal elemento es también determinante o reproductivo de tales formas sociales, es decir, plantearía que lo político es productivo y reproductivo; las condiciones sociales se producirían en una dinámica política de lucha de fuerzas para establecer una situación de tales fuerzas como poder reproductivo que reproduciría tales condiciones e incluso las agudizaría. El poder, entonces, se plantearía como una instancia determinante de lo social que produciría en una segunda, un estado o relación de fuerzas que produciría los fenómenos sociales concretos, por lo que la labor genealógica consistiría en hacer la historia de estos procesos determinantes de lo político, y con ello, de lo social. Los estudios que propone Foucault sobre el poder parten del estudio de esos procesos sociales de luchas de fuerzas que lo determinan y relacionan de una manera particular. De tal manera, propone que las sociedades se van a caracterizar por el tipo de poder que reproduzca las relaciones sociales de cada sociedad.

Los estudios genealógicos propuestos por Foucault son fundamentalmente los de la sociedad soberna y la sociedad disciplinaria, dos tipos de sociedad producidas a partir de un tipo específico de poder. Las sociedades soberanas tienen como modalidad del poder las características del poder despótico, es decir, la corporalidad, la espectacularidad y lo ceremonial, un poder que ejerce el déspota de manera corporal y ceremonial, por lo que Foucault recurre al ejemplo de los suplicios por su exhibición, espectacularidad y corporalidad para mostrar el ejercicio de un poder que se caracteriza por establecer y reproducir las relaciones sociales a partir de estas características, como los principios de un poder que se centra en el soberano, y por ello, en su cuerpo, por lo que el castigo se ejerce sobre otro cuerpo que es el de los súbditos, que con su ilicitud agreden el cuerpo del soberano, un tipo de poder que responde a una forma social feudal; mientras que las sociedades disciplinarias que son las formas propias de la modernidad, reproducen un tipo de poder adecuado para la forma capitalista, por lo que, la disciplina que es su principio consiste en una relación de fuerzas que tiene por objetivo la modulación de las fuerzas de los seres humanos para que pasen de siervos a obreros, una técnica para modificar las fuerzas de sus cuerpos individuales para que sean capaces de articularse en grandes colectivos sociales propios de las nuevas formas de las sociedad capitalista, colectivos de obreros que articulen sus fuerza en la producción, por lo que la disciplina se caracterizará por producir cuerpos productivos, para lo cual, recurre a las dinámicas del 
panóptico que consisten en espacios cerrados para la vigilancia, la organización y el castigo que produzcan comportamientos productivos en instituciones como la escuela, el ejército o la fábrica. ${ }^{10}$

El cuerpo humano entra en un mecanismo de poder que lo explora, lo desarticula y lo recompone. Una «anatomía política», que es igualmente una «mecánica del poder», está naciendo; define cómo se puede hacer presa en el cuerpo de los demás, no simplemente para que ellos hagan lo que se desea, sino para que operen como se quiere, con las técnicas, según la rapidez y la eficacia que se determina. La disciplina fabrica así cuerpos sometidos y ejercitados, cuerpos «dóciles», La disciplina aumenta las fuerzas del cuerpo (en términos económicos de utilidad) y disminuye esas mismas fuerzas (en términos políticos de obediencia) (Foucault, 2001: 141).

Este planteamiento es retomado por Deleuze en su texto Postescriptum: sobre las sociedades de control, en el cual, retomando los planteamiento de Foucault propone que estamos entrando en un nuevo proceso histórico que producirá un nuevo tipo de sociedad organizado a partir de una nueva modalidad del poder, ${ }^{11}$ un poder basado en las tecnologías de la informática y las telecomunicaciones que implican nuevas formas no solamente de la producción, que era la prioridad en la sociedad disciplinaria, sino, de la circulación del capital, el comercio internacional y la acumulación de riqueza a través de los usos de las tecnologías por parte de las nuevas empresas de los servicios tecnológicos y la especulación financiera. Esta nueva sociedad es definida por Deleuze recuperando a Foucault como una sociedad del control, cuyo poder se caracterizará por los nuevos usos de la tecnología que se ejercerá en espacios abiertos, a través de archivos y registros informáticos y de tecnologías que además de vigilar pueden predecir el comportamiento, controlando los comportamientos indeseables de poblaciones marginadas de las nuevas formas de la producción y el consumo; formas sociales adecuadas paras las nuevas formas del capitalismo que prescinde de la mayor parte de la población por una producción automatizada y las nuevas formas de circulación del capital que requieren de mercados

10 «Foucault situó las sociedades disciplinarias en los siglos XVII y XIX, y estas sociedades alcanzan su apogeo a principios del siglo XX. Operan mediante la organización de grandes centros de encierro. El individuo pasa sucesivamente de un círculo cerrado a otro, cada uno con sus propias leyes: primero la familia, después la escuela ("ya no estas en la casa"), después el cuartel ("ya no estás en la escuela"), a continuación la fábrica, cada cierto tiempo el hospital, y a veces la cárcel, el centro de encierro por excelencia (Deleuze, 1996: 247)».

11 «Pero Foucault conocía también la escasa duración de este modelo: fue el sucesor de las sociedades de soberanía, cuyos fines y funciones eran completamente distintos: gravar la producción más que organizarla, decidir la muerte más que administrar la vida; la transición fue progresiva. Napoleón parece ser quien realizó la transformación de una sociedad en otra. Pero, también las disciplinas entraron en crisis en provecho de nuevas fuerzas que iban produciendo lentamente, y que se precipitaron después de la segunda guerra mundial: las sociedades disciplinarias son nuestro pasado inmediato, lo que estamos dejando de ser (Deleuze, 1996: 247)». 
internacionales y simultáneos integrados a través de las tecnologías. En tales términos Deleuze afirma:

Se trata de las sociedades de control, que están sustituyendo a las disciplinarias. «Control» es el nombre propuesto por Burroughs para designar al nuevo monstruo que Foucault reconoció como nuestro futuro inmediato. También Paul Virilio ha analizado continuamente las formas ultrarrápidas que adopta el control «al aire libre» y que reemplazan a las antiguas disciplinas que actuaban en el período de los sistemas cerrados (Deleuze, 1996: 247).

\section{Conclusión}

A partir de los fenómenos descritos que se presentan como los signos de una nueva época, es decir, como la manifestación y expresión de las relaciones de las fuerzas sociales en su reordenamiento a partir de las innovaciones tecnológicas en la sociedad capitalista; proponemos la necesidad y posibilidad de una aproximación a tales fenómenos desde la perspectiva política genealógica, que permitiría interpretar tales manifestaciones como las transformaciones sociales de un nuevo tipo de poder que a partir de la radicalización de la dinámica capitalista de valorización del valor -producción, concentración y acumulación de riqueza- plantea un nuevo tipo de relaciones de poder y forma de la sociedad, en las cuales, la sociedad se organizaría en torno a un nuevo centro mundial de acumulación radical de la riqueza social, un apartheid mundial online, que a partir de los usos de las tecnologías de la información despojaría de manera radical de la riqueza social y natural al resto de la humanidad, convirtiendo a los seres humanos en desposeídos radicales, no solamente privados de la posibilidad de formar parte de la nueva sociedad productiva y consuntiva, sino también, de las condiciones elementales naturales y sociales de vida al saquear los recursos naturales de sus territorios o despojándoles de ellos, como testimonian los procesos migratorios de poblaciones cuyas condiciones de vida han sido destruidas en sus lugares de origen. Es decir, que el método genealógico permitiría entender los fenómenos contemporáneos como los signos de la transformación social de una nueva época, la era digital, en la que se radicalizarán estás condiciones y relaciones sociales entre quienes se encontrarán on line participando del centro de acumulación de riqueza, en la forma de bienes y servicios, y quienes quedarán off line, que serán cada vez más poblaciones en la dinámica radicalizada de privatización de los recursos y acumulación de riqueza.

La definición de la nueva época depende entonces de la manera en que los poderes actuales se posicionen frente a los poderes anteriores, sobre todo, en relación con los gobiernos nacionales y sus instituciones sociales, y a partir de ello, establezcan institucionalmente las dinámicas y estructuras de sus procesos de acumulación de riqueza, y con ello, las modalidades de la inclusión y la exclusión en el apartheid 
mundial, es decir, establezcan con claridad el alcance de su poder. Por ello, la definición de la nueva sociedad de control consistirá en una pugna y negociación con las estructuras políticas y jurídicas estatales, en las que conceptos como ciudadanía y derechos humanos pasan de ser una legitimación para las formas de producción y consumo de sociedades capitalistas con base en el Estado nación, a límites indeseables para los efectos de la concentración de riqueza radical y la pauperización de poblaciones, por lo que es muy probable la implementación de políticas cada vez más intolerantes con los el extranjero y autoritarias al interior de las sociedades como una forma no solamente de contener la crítica y la movilización sino también de encausar la inconformidad y la violencia provocada por la estructura excluyente de la sociedad. En estos términos, la capacidad de organización y respuesta de las poblaciones y comunidades locales, su poder, es el otro factor decisivo de la definición de la nueva sociedad, sólo si asume un carácter intempestivo, es decir, si los individuos y colectivos asumen una oposición a las dinámicas de la mercantilización generalizada que interrumpa la dinámica del cálculo instrumental, explorando no solamente alternativas a los usos de la tecnología, sino sobre todo, buscando y desarrollando nuevas formas de colectividad que les permitan franquear los límites de los guetos en los que se busca confinarles, puesto que parte de la fuerza del poder como control se basa en la descomposición de las relaciones sociales, y con ello, en el debilitamiento y la vulnerabilidad de los individuos aislados.

En medio de la incertidumbre de la indefinición de los tiempos y actores de la sociedad del control, desde que fue formulada por Deleuze en la década de los noventa, se presenta como apremiante la necesidad de no solamente contemplar con temor o esperanza la transformación de la sociedad, sino, de buscar formas de resistencia y lucha, es decir, las nuevas armas que quizá en parte se encuentren en esas mismas tecnologías utilizadas de otra forma y con otros propósitos, ${ }^{12}$ pues desde de una perspectiva genealógica nada está decidido anticipadamente sino que se decide en la interacción de las fuerzas sociales que además de inciertas pueden ser intempestivas.

\section{Bibliografía}

Deleuze, G. (1996). Conversaciones. Valencia: Pre-textos.

Deleuze G. (2008). Nietzsche y la filosofía. Madrid: Anagrama.

\footnotetext{
12 «No cabe comparar para decidir cuál de los dos regímenes es más duro o más tolerable, ya que tanto las liberaciones como las sumisiones han de ser afrontadas en cada uno de ellos a su modo. Así, por ejemplo, en la crisis del hospital como medio de encierro, es posible que la sectorialización, los hospitales de día o la asistencia domiciliaria hayan supuesto en un principio nuevas libertades; ello no obstante, participan igualmente de mecanismos de control que no tienen nada que envidiar a los más terribles encierros. No hay lugar para el temor ni para la esperanza, sólo cabe buscar nuevas armas (Deleuze, 1996: 247)».
} 
Foucault M. (1979). La microfísica del poder. Madrid: Ediciones de La Piqueta.

Foucault M. (2001). Vigilar y castigar. México: Siglo XXI.

Marx K. (1995). El Capital. México: Fondo de Cultura Económica.

Nietzsche F. (2000). La genealogía de la moral. Madrid: Alianza Editorial.

Subcomandante Marcos (2017). Escritos sobre la guerra y la economía política.

México: Pensamiento Crítico Ediciones. 